\title{
Modification of Penfield dissector as monopolar cautery point for transoral odontoidectomy
}

Transoral surgery for craniovertebral junction anomaly is a challenging task for a neurosurgeon because it involves operating through a very constrained space and at greater depth. Dissection of posterior pharyngeal wall muscles from $\mathrm{C} 1$ and $\mathrm{C} 2$ can be facilitated by the use of monopolar cautery. Most of the conventional monopolar cautery attachments are either not long enough or can impede vision due to their thickness. Moreover, they are not insulated up to the tip, and hence can cause mucosal injury leading to delayed healing.

Keeping these facts in mind, we have designed a new monopolar cautery attachment for transoral surgery. Penfield dissector no. 4 is a narrow and long instrument, and like all neurosurgeons, we are quite comfortable using it. Therefore, we made the following modifications in this dissector to convert it into a monopoar cautery point attachment [Figure 1]:

1. The posterior part of the no. 4 Penfield dissector is drilled out to create a hole into which an exclusively designed electrical jack is fitted

2. Insulation is provided by covering almost the entire length of the instrument except the tip by a plastic sheath. A red rubber catheter is also used to cover the length of the instrument. It provides not only insulation but also a non-slippery grip

3. Electrical attachment consists of two jacks and an intervening wire capable of carrying up to $80 \mathrm{~V}$. One end of the jack is designed in such a way that it may be inserted into the drilled end of the Penfield dissector as described above and the other end fits in the socket of the conventional monopolar cautery machine.

\begin{tabular}{|l|l|}
\hline \multicolumn{2}{|c|}{ Access this article online } \\
\hline Quick Response Code: & Website: \\
\hline & www.ijns.in \\
\cline { 2 - 2 } & \\
\hline
\end{tabular}

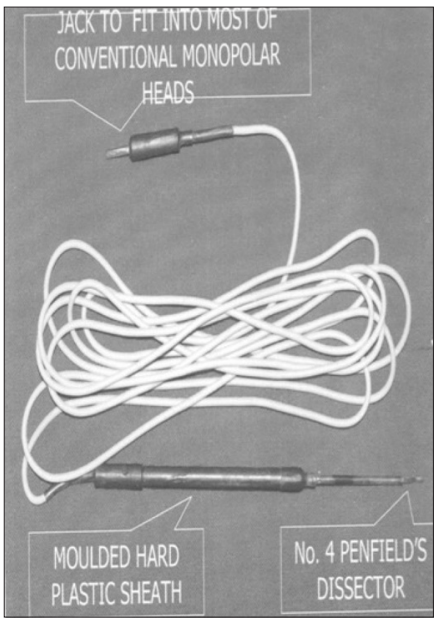

Figure 1: Monopolar cautery with its plastic molded sheath, attachment cord, and jack that fits in the cautery unit

The entire length of this cautery point is about $21 \mathrm{~cm}$. This is long enough to aid in transoral surgical procedure. Moreover, it is narrow and thus vision is not obscured. We are using this instrument and more than 100 transoral surgical procedures have been performed by the senior author using it.

We have taken a patent for this device and are in the process of developing a commercial adaptation of it.

Nirmal Thakur, Vivek Tandon ${ }^{1}$, P. Sarat Chandra ${ }^{1}$ Jai Prakash Narain Apex Trauma Centre, ${ }^{1}$ Department of Neurosurgery, All India Institute of Medical Sciences, New Delhi, India

Address for correspondence: P. Sarat Chandra Additional Professor, Room 7, $6^{\text {th }}$ Floor, CN Center, AlIMS, Ansari Nagar, New Delhi - 110 029, India. E-mail: saratpchandra3@gmail.com

How to cite this article: Thakur N, Tandon V, Chandra PS. Modification of Penfield dissector as monopolar cautery point for transoral odontoidectomy. Indian J Neurosurg 2012;1:89.

Source of Support: Nil, Conflict of Interest: None declared. 